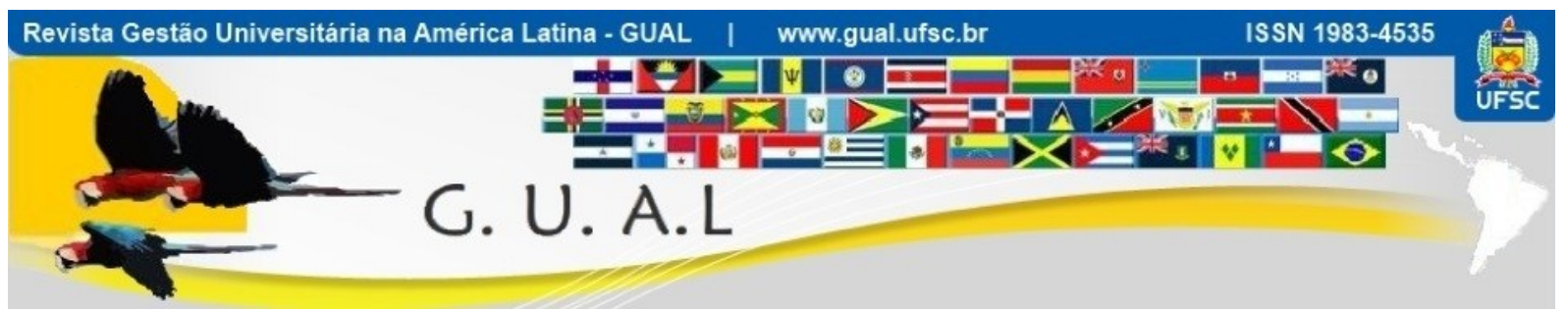

\title{
GESTÃO PÚBLICA DA UFPI: UMA ANÁLISE DO SEU PLANO DE DESENVOLVIMENTO INSTITUCIONAL (PDI)
}

\section{THE PUBLIC MANAGEMENT OF UFPI: AN ANALYSIS OF ITS INSTITUTIONAL DEVELOPMENT PLAN}

Adalgisa Costa Melo, Especialista

Universidade Federal do Piauí - UFPI adalgisamelo@ufpi.edu.br

Delmárcio de Moura Sousa, Especialista Universidade Federal do Piauí - UFPI delmarciomoura@,ufpi.edu.br

Eulálio Gomes Campelo Filho, Doutor Universidade Federal do Piauí - UFPI eulaliocampelo@ufpi.edu.br

Marcos Ferasso, Mestre Universidade Federal do Piauí - UFPI mferasso@ufpi.edu.br

Recebido em 30/janeiro/2012

Aprovado em 13/junho/2012

Sistema de Avaliação: Double Blind Review

Esta obra está sob uma Licença Creative Commons Atribuição-Uso. 


\begin{abstract}
RESUMO
Este estudo foi desenvolvido com o intuito de levantar dados a respeito dos modelos de gestão que se destacaram ao longo da nossa história e compreender a importância do planejamento estratégico para as instituições públicas. Pretende-se ainda identificar qual o modelo de gestão adotado pela Universidade Federal do Piaú e analisar o seu Plano de Desenvolvimento Institucional (PDI), comparando as ações propostas com os resultados até então obtidos. A metodologia utilizada foi uma pesquisa exploratória do tipo estudo de caso, aliada a uma abordagem bibliográfica e documental, desenvolvidos com base em princípios de pesquisa analítica, por meio da análise temática de conteúdos. Constatou-se que a UFPI adota um modelo híbrido de gestão, apresentando elementos característicos tanto da gestão burocrática quanto da gerencialista e que é uma instituição capaz de gerir estrategicamente as suas ações.
\end{abstract}

Palavras-chave: Modelos de gestão. Planejamento estratégico. Universidade Federal do Piauí (UFPI). Campus Amílcar Ferreira Sobral (CAFS). Plano de Desenvolvimento Institucional (PDI).

\begin{abstract}
This article was developed in order to collect data regarding the management models that stood out throughout the years and understand the importance of strategic planning for public institutions. Another goal was to identify the management model adopted by the Federal University of Piauí (UFPI) and analyze their Institutional Development Plan (PDI), comparing the actions proposed in the plan and the practical results obtained so far. The methodology used was the case study with an exploratory perspective, which included a bibliographical and documentary approach developed based on principles of the analytical research. In this study, it was found that the UFPI has been able to manage strategically its processes, at the same time that adopts a hybrid management style, containing characteristic features of both the managerial and the bureaucratic management models.
\end{abstract}

Key words: Management model. Strategic planning. Institutional Development Plan (PDI). 


\section{GESTÃO PÚBLICA DA UFPI: UMA ANÁLISE DO SEU PLANO DE DESENVOLVIMENTO \\ INSTITUCIONAL (PDI) \\ DOI: http://dx.doi.org/10.5007/1983-4535.2012v5n2p16}

\section{INTRODUÇÃO}

Conforme a nossa Constituição, em seu artigo 37, "a administração pública direta e indireta de qualquer dos Poderes da União, dos Estados, do Distrito Federal e dos Municípios obedecerá aos princípios da legalidade, impessoalidade, moralidade, publicidade e eficiência", princípios estes que surgem como desafios às entidades e que devem nortear as atividades administrativas.

A Lei n ${ }^{\circ}$ 9784/1999, que regula o processo administrativo no âmbito da Administração Pública Federal, em seu artigo $2^{\circ}$ enfatiza que "a Administração Pública obedecerá, dentre outros, aos princípios da legalidade, finalidade, motivação, razoabilidade, proporcionalidade, moralidade, ampla defesa, contraditório, segurança jurídica, interesse público e eficiência". Este último item, eficiência, foi incluído na Constituição Federal somente em 1999, e através da sua inclusão, enseja-se uma maior aproximação do setor público com a administração do setor privado.

Para Osório (2005), os setores públicos e privados apresentam aproximações, pois há uma tendência, no primeiro, em incorporar normas técnicas típicas do setor público e, no último, em preocupar-se com o quesito da produtividade, típico do setor privado. Ainda segundo ele, para se falar em eficiência e qualidade da gestão pública é necessário que haja a consolidação de uma máquina administrativa estável e bem estruturada.

Dentro desse contexto, percebe-se que os gestores públicos, além de seguir os princípios gerais que norteiam o seu trabalho, devem preocupar-se com o desenvolvimento de um planejamento estratégico adequado - afinal, o ato de planejar estrategicamente deve ser uma prática utilizada por todas as organizações públicas, pois é um poderoso instrumento que visa sistematizar objetivos para um longo prazo e, no caso de possíveis eventualidades nos ambientes externo e interno, propor alternativas para garantir a excelência da organização.

Logo, este artigo objetiva levantar dados a respeito dos modelos de gestão que se destacaram ao longo da nossa história e discutir a importância do planejamento estratégico para as instituições públicas. Busca, ainda, analisar o Plano de Desenvolvimento Institucional (PDI) da Universidade Federal do Piauí, comparando as ações propostas com os resultados até então obtidos. Para alcançar os objetivos propostos, voltamo-nos para um estudo de caso aliado a uma abordagem bibliográfica e documental, desenvolvidos com base em princípios de pesquisa analítica e por meio da análise temática de conteúdos. 
O trabalho está dividido em quatro seções. Nas duas primeiras tem-se o enquadramento teórico, em que foram abordados temas relacionados com os principais modelos de gestão que se destacaram ao longo da nossa história, dentre eles, o patrimonialista, o burocrático e o gerencialista. Buscou-se ainda neste tópico, definir o conceito de planejamento estratégico, destacando seus principais componentes.

A terceira seção trata da metodologia utilizada e das técnicas e instrumentos de recolha e análise de dados. Em seguida, tem-se a apresentação dos resultados da pesquisa, que aborda dados referentes à Universidade Federal do Piauí, como sua oficial instalação, estrutura, seus campi e objetivos, bem como dados referentes ao Campus Amílcar Ferreira Sobral, voltandose para a classificação do modelo de gestão adotado pela instituição e para a análise do seu Plano de Desenvolvimento Institucional. Por fim, apresentar-se-ão as considerações finais, em que se vislumbrarão os pontos positivos ou negativos do planejamento estratégico ora analisado, apresentando-se sugestões para melhorias nos planejamentos futuros.

\section{MODELOS DE GESTÃo PÚBLICA}

Diferentemente das organizações privadas, que efetivamente apresentam maior flexibilidade e empreendedorismo, as organizações públicas são mais rígidas, realizando somente aquilo que é permitido em lei. No entanto, as práticas administrativas podem variar de acordo com cada administração, aproximando-se, neste ponto, das empresas privadas, afinal, as rotinas são praticamente idênticas, e prevalecem em ambas a racionalização, a especialização e o treinamento.

Não basta que a gestão esteja voltada apenas para a eficiência, eficácia e produtividade; é necessário, antes de tudo, que a sua base administrativa esteja bem estruturada e qualificada, apta a corresponder aos anseios da sociedade.

A gestão pública, conforme preconiza Santos (2010, p. 15),

É a arte de planejar, organizar, coordenar, comandar e controlar assuntos de interesse coletivo por meio da mobilização de estruturas e recursos do Estado. Ela visa o bem estar da comunidade, zelando pela manutenção de bens e serviços públicos e pelo enfrentamento de situações consideradas problemáticas.

Bresser-Pereira (1999 apud BERGUE, 2010) propõe a existência de três modelos de gestão: patrimonialista, burocrático e gerencialista. Bergue $(2010$, p. 68) destaca ainda que, dentre os modelos citados acima, "a Administração Pública no Brasil, de fato, pode ser 
percebida como uma combinação, por sobreposição, dos traços que compõem a tipologia proposta por Bresser-Pereira”.

\subsection{Modelo patrimonialista}

No modelo patrimonialista, o poder é exercido de forma a garantir privilégios e vantagens a uma elite centralizadora. Segundo Schmitt e Fiates (2007, p. 5), esse modelo "esteve muito presente na esfera político-administrativa brasileira, notadamente no período colonial, em que o Estado atuava como ente central na organização e na provisão de todas as ações de políticas públicas e sociais". Nesse sentido, por utilizar os recursos públicos em prol de uma minoria, em detrimento de uma ampla coletividade necessitada de atendimento, esse modelo feria um dos princípios básicos da administração pública, o princípio da impessoalidade, pelo qual os serviços públicos devem ser oferecidos sem preferências ou distinções.

Na gestão patrimonialista, os objetivos são definidos com base em interesses pessoais, e não com base nos objetivos organizacionais, evidenciando-se, mais uma vez, a forte presença da pessoalidade e do desvio de finalidade nesse modelo de gestão, que, como sabemos, deveria focar-se no princípio da indisponibilidade do interesse público, segundo o qual o interesse público não pode ser livremente disposto pelo gestor.

\subsection{Modelo burocrático}

No modelo burocrático, difundido pelo cientista alemão Max Weber, há ênfase na racionalidade das leis e, consequentemente, na obediência, que implicam mais disciplina, precisão e rigor.

De acordo com um dicionário etimológico, a palavra "burocracia" tem origem nos termos linguísticos "bureau" e "cracia"; o primeiro, de origem francesa, significa "escritório", e o segundo, uma terminologia grega correspondente a "administração". Diante dessa etimologia, "burocracia" enfatiza a ideia do exercício do poder por meio dos escritórios e das repartições públicas, desenvolvendo-se com base na formalidade, na impessoalidade e no profissionalismo. Ela surge como forma de combater a corrupção e o nepotismo tão presentes no modelo patrimonialista, em que não havia uma diferenciação entre os bens públicos e os bens privados, pois, para os detentores do poder, ambos lhes pertencem, sem distinção. 
Segundo Weber (2000), a gestão burocrática apresenta as seguintes características:

- a racionalidade e a superioridade das normas;

- a impessoalidade das relações;

- a autoridade e as competências objetivas; e

- a hierarquia oficial para controle e supervisão.

$\mathrm{O}$ autor destaca alguns atributos associados aos membros do quadro administrativo burocrático: os servidores são pessoalmente livres, obedecendo somente às obrigações objetivas de seu cargo; são nomeados (e não eleitos); têm competências funcionais fixas; sua qualificação profissional é verificada mediante prova e certificada por diploma; são remunerados por salários fixos em dinheiro; exercem seus cargos como profissão única ou principal; têm perspectiva de uma carreira (progressão); trabalham em "separação absoluta dos meios administrativos" e sem apropriação do cargo; estão submetidos a um sistema rigoroso e homogêneo de disciplina e controle do serviço.

É com base em seus atributos que Lacombe e Heilborn (2008, p. 476) tratam da desburocratização nas organizações públicas, apresentando a seguinte definição: “desburocratizar é administrar de forma mais humana e eficaz, confiando mais e punindo os que não correspondem à confiança, dando mais valor às palavras e aos fatos do que aos documentos". Os autores enfatizam também o que para eles seria a principal dificuldade de mudança num sistema burocrático, a sua rigidez, pois a burocracia não permite a adaptação rápida e simples à mudança, tendendo a resistir à transformação.

Hampton (2005) afirma que há duas faces da burocracia, uma repulsiva e a outra atraente. A repulsiva diz respeito à sua inflexibilidade; a atraente, por sua vez, às regras e ao tratamento impessoal, protegendo os cidadãos/usuários de desvios imprevisíveis, injustos e caprichosos. Para Chiavenato (2003), os pontos fortes desse modelo são a racionalidade, os cargos precisamente delimitados e a rapidez nas decisões. Entretanto, o autor apresenta as seguintes limitações do modelo burocrático: a especialização (que faz com que cada órgão focalize seus próprios objetivos em detrimento dos objetivos gerais da organização); a rigidez e a inflexibilidade (que gera uma total aversão à adaptabilidade, ajustamento, inovação e mudança); o fato de o componente humano ser ignorado.

Diante disso, reconhecemos a necessidade de promovermos mudanças nas organizações, no sentido de potencializá-las e flexibilizá-las, uma vez que a nossa sociedade exige presteza, empreendedorismo e eficiência - afinal, uma vez que desempenham serviços direcionados ao público, este tem o direito de exigir qualidade, eficiência e eficácia, sem que 
se deixem de lado, logicamente, os atos burocráticos que contribuem para o bom andamento do sistema público.

\subsection{Modelo gerencialista}

Por fim, o modelo gerencialista, também denominado de "nova administração pública”, é um modelo pós-burocrático de organização baseado em valores de eficiência, eficácia e competitividade, conforme salienta Sechi (2009). Verifica-se que a sua estrutura se caracteriza pela orientação para clientes e resultados, pela competitividade administrativa, flexibilidade, descentralização e estruturas horizontalizadas (ARAGÃO, 1997).

Apesar de apresentarem características próprias, os modelos patrimonialista, burocrático e gerencialista têm em comum a preocupação com a função de controle, seja através do controle dos seus agentes e processos, do controle das relações intraorganizacionais ou do controle sobre a produtividade/competitividade e sobre os resultados.

Mudar uma cultura tão enraizada não e fácil; é necessário o empenho de toda a equipe, a fim de desenvolverem-se novas aptidões, aumentar-se a produtividade e promover-se a satisfação daqueles aos quais os serviços são direcionados. Nesse sentido, cabe à nova geração de servidores públicos, selecionados via concurso público e não por indicação, como acontecia antigamente, não se deixar influenciar pela rigidez do sistema e promover mudanças no comportamento organizacional e nas suas atitudes, procurando desenvolver novas capacidades a fim de inovar o ambiente organizacional, garantindo mais presteza, eficiência, eficácia, clareza e transparência, independentemente do modelo de gestão que predomine.

\section{PLANEJAMENTO ESTRATÉGICO}

O termo "planejamento", conforme Lacombe e Heilborn (2008, p. 162), pode ser visto como a determinação da direção a ser seguida para alcançar um resultado desejado e a determinação consciente de cursos de ação, isto é, de rumos.

Para Maximiano (2009, p. 114), o planejamento,

Além de ser um processo de tomada de decisões, é uma dimensão das competências intelectuais. Para a moderna psicologia, planejar é uma função cognitiva superior, um tipo refinado de habilidade. A decisão e a capacidade de lidar com o futuro por meio do planejamento refletem, portanto, uma forma de inteligência. 
Quanto ao termo “estratégia", Luft (2004, p. 306) nos remonta aos conceitos descritos abaixo:

1. Arte de dirigir ou aplicar os recursos bélicos, planejar as operações de guerra, etc.

2. Habilidade em dispor as coisas para alcançar uma vitória; ardil; manha; astúcia.

Inicialmente, estratégia "representava um meio de vencer o inimigo, um instrumento de vitória na guerra" (GRAVE; MENDES, 2001 apud CAMARGOS; DIAS, 2003). Atualmente, compreende tanto as situações de concorrência quanto as de colaboração entre as organizações (MAXIMIANO, 2009).

\subsection{Conceito de planejamento estratégico}

Para Barbosa e Brondani (2005, p. 2), o planejamento estratégico

surge como uma valiosa ferramenta de auxílio à alta administração, pois permite nortear as ações gerenciais da empresa dentro de um plano previamente determinado de metas e estratégias, diminuindo, com isso a possibilidade de tomada de decisões equivocadas, num mercado extremamente competitivo sem margem para erro.

Lacombe e Heilborn (2008, p. 163) nos trazem o seguinte conceito de planejamento estratégico:

O planejamento estratégico refere-se ao planejamento sistêmico das metas de longo prazo e dos meios disponíveis para alcançá-las, ou seja, aos elementos estruturais mais importantes da empresa e à sua área de atuação, e considera não só os aspectos internos da empresa, mas também, e principalmente, o ambiente externo no qual a empresa está inserida.

Diante da sua área de atuação, que, como vimos, envolve tanto o ambiente interno quanto o externo, o planejamento estratégico é efetuado pelos dirigentes do topo da hierarquia - os diretores e os assessores -, pois eles possuem uma visão mais ampla a respeito da instituição, proporcionando um maior grau de eficácia - afinal, resultados válidos precisam ser obtidos.

Segundo Fischmann e Almeida (2009, p. 25),

Planejamento estratégico é uma técnica administrativa que, através da análise do ambiente de uma organização, cria a consciência das suas oportunidades e ameaças dos seus pontos fortes e fracos para o cumprimento da sua missão e, através desta consciência, estabelece o propósito de direção que a organização deverá seguir para aproveitar as oportunidades e evitar riscos. 
Percebe-se, então, que, ao planejar, primeiramente deve ser feita uma análise do ambiente, a fim de identificar se as estratégias propostas são condizentes ou não com a realidade, pois há determinadas situações externas que afetam a organização e que não cabe a ela modificá-las, como, por exemplo, uma crise econômica, redução de gastos públicos, valor das ações, taxa de juros etc. Após essa análise externa, o órgão responsável pelo planejamento deve voltar-se para o interior da organização, efetuando um diagnóstico com a finalidade de identificar os seus pontos fortes e fracos, já que se trata de um planejamento de prazo longo e estritamente relacionado com o conceito de eficácia.

\subsection{Componentes do planejamento}

Os planejamentos possuem componentes básicos que os caracterizam e fornecem aos gestores a direção a ser seguida, sendo que a listagem desses componentes varia de autor para autor.

Conforme Maximiano (2008), em todo planejamento devem constar os objetivos, os meios para sua realização e os meios de controle. Para o referido autor, quando se trata de planejamento estratégico, os seguintes componentes devem estar presentes: a missão (a razão de ser da organização), o desempenho da organização (os resultados efetivamente alcançado), os desafios e oportunidades do ambiente, bem como os pontos fortes e fracos dos sistemas internos da organização e as competências dos planejadores (seus conhecimentos de técnicas, suas atitudes em relação ao futuro e seu interesse em planejar).

Fischmann e Almeida (2009) abordam os componentes da seguinte forma: primeiramente, deve ser feita uma avaliação da estratégia vigente, identificando-se os caminhos que a organização vem seguindo e qual sua função. Após essa etapa, avalia-se o ambiente, identificando-se as oportunidades e ameaças e os pontos fortes e fracos para o cumprimento da sua missão. Em seguida, volta-se para dentro da organização, procurando estabelecer o seu perfil estratégico, ou seja, a direção a ser seguida para aproveitar as oportunidades e evitar ameaças; parte-se então para a quantificação dos objetivos e para a finalização do planejamento, concretizado através do resumo do planejamento estratégico. Por fim, parte-se para a divulgação, que consiste em transmitir aos elementos de decisão da organização o que se espera na sua alçada de atuação.

Já Lacombe e Heilborn (2008, p. 166) destacam os componentes relacionados abaixo: 
Premissas básicas - Diagnóstico - Estimativas - Projeções - Cenário - Objetivos - Metas -

Políticas - Procedimentos - Planos - Programas - Projetos - Cronogramas - Orçamentos

Para eles, as premissas básicas são os princípios mais gerais que inspiram todas as atividades da instituição. O diagnóstico diz respeito ao exame da situação de uma empresa, consubstanciando-o em conclusões sobre os aspectos analisados com sugestões do que se deve fazer. As estimativas são uma avaliação qualitativa ou quantitativa, e as projeções, operações quantitativas em que uma configuração presente de acontecimentos se transforma em outra futura, mediante regras preestabelecidas. As metas são resultados a serem atingidos como consequência de um plano, programa ou projeto com um prazo previsto para sua execução e os objetivos, propósitos permanentes e serem atingidos.

As políticas correspondem a um conjunto de declarações escritas a respeito das intenções da instituição em relação a determinado assunto, e os procedimentos são as formas de atuação estabelecidas por critérios predeterminados para orientar decisões recorrentes. Finalmente, há os planos, os programas e os projetos. Os primeiros são instrumentos que expressam concretamente o propósito geral do planejamento e que possibilitam a programação das ações e atividades necessárias para sua realização; os programas fazem parte dos planos, abrangendo desdobramentos específicos; já os projetos são parte de um programa ou de um plano cuja responsabilidade pela execução é claramente atribuída a uma empresa ou parte dela.

Por fim, sublinhamos a visão de Chiavenato (2010), na qual o planejamento estratégico se assenta sobre três parâmetros: a visão para o futuro, os fatores ambientais externos e os fatores organizacionais internos.

Em virtude do exposto, verifica-se que o planejamento estratégico é um instrumento de gestão de grande valia para as organizações, e é através dele que o gestor e sua equipe estabelecem os parâmetros orientadores do seu plano de ação.

\section{METODOLOGIA}

Para a concretização do estudo realizado, fez-se necessário um estudo de caso aliado a uma pesquisa bibliográfica e documental, desenvolvidos com base em princípios da técnica de pesquisa analítica, por meio da análise temática de conteúdos. 
Segundo Collis e Hussey (2005, p. 24), “a pesquisa analítica vai além da descrição das características, analisando e explicando por que ou como os fatos estão acontecendo", logo, optamos por realizar uma investigação desta natureza porque pretendemos analisar, dentro do Plano de Desenvolvimento Institucional da UFPI, itens específicos do plano, selecionados com base em atividades administrativas, como, por exemplo, estrutura física, ampliação de cursos noturnos, modernização de laboratórios, estímulo à qualificação etc.

\section{A UNIVERSIDADE FEDERAL DO PIAUÍ (UFPI)}

A Universidade Federal do Piauí é uma instituição de respaldo em todo o país. Oficialmente instituída em 12 de março de 1971, teve sua origem na junção de algumas faculdades: a Faculdade de Direito do Piauí, a Faculdade de Medicina do Piauí, a Faculdade Católica de Filosofia do Piauí, a Faculdade de Enfermagem e Odontologia do Piauí e a Faculdade de Administração do Piauí (PDI- UFPI, p. 29).

A UFPI é a maior universidade pública do Piauí, e é mantida pelo Ministério da Educação, por meio da Fundação Universidade Federal do Piauí (FUFPI). Além de incentivar a área educacional, com vagas nos mais variados cursos, essa universidade também proporciona a criação de vagas de emprego, desenvolvendo a capital e outras localidades, como Bom Jesus (Campus Cinobelina Elvas), Floriano (Campus Amílcar Ferreira Sobral), Parnaíba (Campus Ministro Reis Veloso) e Picos (Campus Senador Helvídeo Nunes de Barros). Conta, ainda, com três Colégios Agrícolas: o Colégio Agrícola de Teresina (CAT), o Colégio Agrícola de Floriano (CAF) e o Colégio Agrícola de Bom Jesus (CABJ).

Abaixo, podemos identificar os princípios norteadores da atuação da UFPI, constantes no seu planejamento estratégico (p. 26):

\section{Princípios norteadores da atuação da UFPI}

I- compromisso com a justiça social, equidade, cidadania, ética, preservação do meio ambiente, transparência e gestão democrática;

II- verticalização do ensino e sua integração com a pesquisa e a extensão;

III- difusão do conhecimento científico e tecnológico e suporte aos arranjos produtivos locais, sociais e culturais;

IV - inclusão de um público historicamente colocado à margem das políticas de formação para o trabalho, dentre este, as pessoas que residem em localidades geograficamente distantes dos grandes centros educativos do Estado;

V- natureza pública e gratuita do ensino, sob a responsabilidade da União. 
Percebe-se, então, que a UFPI tem em sua base princípios que devem ser seguidos por todos que formam a instituição, desde aqueles que compõem a sua cúpula até aqueles que desenvolvem suas funções taticamente e operacionalmente.

É através do Programa de Reestruturação e Expansão das Universidades Federais (REUNI) que o ensino superior vem dando um salto na oferta de vagas oferecidas e na reestruturação da parte física destinada à promoção do ensino, pois esse programa "visa favorecer o acesso, a permanência e a conclusão do curso superior e ainda um melhor aproveitamento da estrutura física e de recursos humanos, criando oportunidades direcionadas para este fim" (MEC/REUNI).

A Universidade Federal do Piauí aderiu ao REUNI em 2006, e desde então vimos que a sua meta vem sendo cumprida. Como exemplo, podemos citar o caso do Campus Senador Helvídeo Nunes de Barros, localizado na cidade de Picos/PI, que inicialmente contava apenas com dois cursos de graduação - Licenciatura em Letras e Licenciatura em Pedagogia. Após a sua adesão ao REUNI, o campus passou a oferecer os cursos de Bacharelado em Administração, Bacharelado em Enfermagem, Bacharelado em Nutrição, Bacharelado em Sistemas de Informação, Licenciatura em História, Licenciatura em Ciências Biológicas e Licenciatura em Matemática. Essa ampliação se deu em todos os campi da UFPI, não só nos cursos de graduação, mas também nos de pós-graduação.

Dessa forma, além de promover o ensino, a pesquisa, a extensão e a inclusão social, a UFPI favorece significantemente o crescimento do estado do Piaú.

\subsection{O Campus Amílcar Ferreira Sobral (CAFS)}

Em Floriano, o Campus Amílcar Ferreira Sobral (CAFS) iniciou suas atividades no primeiro semestre de 2009 e oferece vagas de nível superior distribuídas entre os cursos de Administração, Biologia, Enfermagem e Pedagogia, totalizando, no ano de 2011, 704 alunos matriculados.

Visando garantir a permanência dos estudantes na instituição, o CAFS promove políticas como a disponibilização de bolsas com valores e pré-requisitos diferenciados, a fim de contribuir com a formação de seu corpo discente. Segundo dados do relatório disponibilizado pela Pró-Reitoria de Assuntos Estudantis e Comunitários (PRAEC), o CAFS ofereceu 140 bolsas permanência no ano de 2010 e, em 2011, além da ampliação do número de bolsas, estão sendo instalados o Restaurante Universitário e o Programa de Moradia 
Universitária, ambos visando favorecer a permanência dos estudantes em situação de vulnerabilidade econômica e social na instituição. Recentemente, foi aprovado o primeiro Projeto de Doutorado no Campus, uma parceria com a Universidade Federal do Rio de Janeiro (UFRJ), destinado à formação dos professores e servidores que, eventualmente, não possuam o título de doutor.

O Campus Amílcar Ferreira Sobral é um dos principais centros educacionais do Piauí, exercendo influência sobre municípios piauienses e maranhenses. Sua efetiva implantação está contribuindo fortemente para a consolidação do desenvolvimento local.

\subsection{O modelo de gestão adotado pela UFPI}

Dentre os modelos de gestão descritos acima, percebe-se que a Universidade Federal do Piauí adota um modelo híbrido, em que a base estrutural de sua gestão concentra-se no modelo burocrático, embora também apresente vários elementos do modelo gerencialista.

Observa-se que o modelo patrimonialista não mais persiste - afinal, este tipo de gestão não é harmônico com os atuais objetivos almejados pela instituição. A concentração no modelo burocrático se dá pela presença de uma estrutura organizacional formalizada e hierarquizada, centrada na divisão de trabalho e de poder, na padronização dos processos e no forte apego às leis. Além disso, sua atual tendência com enfoque no modelo gerencialista se dá pelo fato de adotar uma gestão envolta por mecanismos de eficiência e eficácia, com uma visão de longo prazo em busca de uma maior transparência das atividades planejadas, uma vez que, no gerencialismo, há uma forte orientação para clientes e resultados.

Ante o exposto, foi possível constatar que a gestão adotada pela UFPI está em transição, apresentando elementos característicos tanto da gestão burocrática quanto da gestão gerencialista.

\subsection{O Plano de Desenvolvimento Institucional (PDI) da UFPI (2010/2014)}

O PDI, aprovado pela Resolução Conjunta $\mathrm{n}^{\mathrm{o}} 2$ de 26 de maio de 2010, é o planejamento estratégico da UFPI, seu plano de gestão, e, como tal, sintetiza sua missão, suas diretrizes e suas proposições políticas para um período de cinco anos:

Este PDI-2010-2014 vem consolidar um importante passo do planejamento estratégico da UFPI, que visa à consecução de ações que resultem no fortalecimento institucional em âmbito administrativo, organizacional e, essencialmente, na melhoria das atividades relacionadas ao ensino, pesquisa 
e extensão, de forma a consolidá-la como instituição geradora e socializadora do conhecimento e fomentadora do avanço científico e tecnológico, em direção ao desenvolvimento da sociedade local, regional e nacional. (PDI-UFPI, p. 14).

No PDI que ora analisamos, dentre as ações propostas, destacamos apenas aquelas estritamente vinculadas às atividades administrativas:

AMPliaÇão da OFERTA de CURSOS E de VAGAS (p. 84, alínea “a”), que já é uma realidade visível; como exemplo, vale ressaltar a ampliação de cursos em todos os campi da UFPI, passando de 48 cursos em 2005 para 92 em 2011, totalizando 5.786 vagas ofertadas apenas em 2011. O CAFS, por ser o campus mais recente da UFPI, iniciou suas atividades oferecendo quatro cursos: Administração, Biologia, Enfermagem e Pedagogia. O número de vagas cresceu significantemente, contando com 200 vagas no seu primeiro ano de instalação e, em 2011, com 360 vagas, sendo 180 preenchidas através do Exame Nacional do Ensino Médio (ENEM) e 180 através do Programa Seriado de Ingresso na Universidade (PSIU), totalizando um número de 704 alunos matriculados naquele ano. Sabe-se que, com a chegada do CAFS em Floriano, os benefícios são visíveis, e têm contribuído significativamente para o desenvolvimento da região; contudo, o CAFS ainda precisa oferecer cursos mais diversificados a fim de criar outras novas oportunidades, condizentes com as potencialidades locais.

OTIMIZAÇÃo DAS FORMAS DE INGRESSO. Segundo o PDI (p. 84, alínea “b”),

O exame de seleção de candidatos a ingressarem a partir de 2010 deverá selecionar e classificar pessoal apenas para preenchimento de $50 \%$ (cinqüenta por cento) das vagas oferecidas nos Cursos de Graduação da UFPI, pois a outra metade das vagas será destinada a candidatos classificados mediante a avaliação dos conhecimentos comuns pertinentes às diversas áreas do Ensino Médio, ou seja, por meio do Exame Nacional do Ensino Médio - ENEM.

Nota-se, através da análise da seleção promovida em 2010 para ingresso em 2011, que a ação aqui proposta também se efetivou, sendo $50 \%$ das vagas preenchidas através do PSIU e a outra parte, pelo ENEM; sabe-se ainda que, para a seleção do vestibular 2011/2012, a UFPI já aprovou a adesão integral ao ENEM. Nas palavras do atual reitor, Luiz de Sousa Santos Júnior, 
Essa foi uma decisão baseada em informações que nós recebíamos da própria sociedade piauiense. Os estudantes estavam ficando bastante sobrecarregados e divididos entre dois processos. O Enem é um modelo mais simples e que possibilita ao candidato concorrer em qualquer universidade do Brasil. (sítio da UFPI).

A alínea “e” do PDI voltou-se para o ESTíMULO À QUALIFICAÇÃo DOCENTE, que tem como meta elevar em pelo menos $25 \%$ o total de ingressos na pós-graduação. Esta é uma ação de sucesso, pois em 2011 se verificaram 27 cursos de mestrado, nas áreas de Agronomia, Educação, Letras, História do Brasil, Políticas Públicas, Química, Ciências e Saúde, Desenvolvimento e Meio Ambiente, Enfermagem, Farmacologia, Ciência Política, Ética e Epistemologia, Matemática, Antropologia e Arqueologia, Genética e Melhoramento, Alimentos e Nutrição, Física, Ciências Farmacêuticas, Biotecnologia, Ciência Animal, Ciência dos Materiais, Geografia, Comunicação, Odontologia e Zootecnia, além de 16 programas de doutorado, nas áreas de Ciência Animal, Desenvolvimento e Meio Ambiente, Políticas Públicas, Educação, Agronomia, História, Filosofia, Ciências da Computação, Ciências da Comunicação, Ciências Médicas, Geografia e Estudos Linguísticos. No CAFS, como já foi citado, está em andamento o seu primeiro programa de doutorado interinstitucional na área de Educação.

Na alínea "g”, a AMPLIAÇÃo DO NÚMERO DE CURSOS NOTURNOS é uma realidade necessária, pois a grande maioria dos estudantes também tem a necessidade de trabalhar. Em 2005, o número de cursos noturnos era apenas sete; em 2011, eram dezoito cursos oferecidos nesse turno. Em Floriano, dos quatro cursos oferecidos, três deles são ofertados nos períodos diurno e noturno, com exceção do curso de Enfermagem, que é realizado somente no período diurno.

Outro item aqui analisado é o que consta na alínea “j” do PDI: a AMPLIAÇÃo DE ÁREAS FÍSICAS E MODERNIZAÇÃO DA INFRAESTRUTURA LABORATORIAL, que também é um fato concreto. Os campi de Picos, Bom Jesus e Parnaíba foram ampliados; no caso do campus de Floriano, este foi totalmente construído, contando com 45 áreas administrativas, 28 salas de aulas, quatorze laboratórios, um auditório com capacidade para 254 lugares, dois anfiteatros, uma biblioteca de 450 metros quadrados, uma videoteca, um setor de reprografia, um biotério, uma central de processamento de dados, banheiros, área de convivência, almoxarifado e um espaço reservado para a Coleção de História Natural.

A Coleção de História Natural da Universidade Federal do Piauí foi instituída pelo Ato da Reitoria UFPI no 467/2011 e, embora recente, constitui-se a primeira coleção oficialmente 


\section{GESTÃO PÚBLICA DA UFPI: UMA ANÁLISE DO SEU PLANO DE DESENVOLVIMENTO \\ INSTITUCIONAL (PDI) \\ DOI: http://dx.doi.org/10.5007/1983-4535.2012v5n2p16}

institucionalizada no estado do Piauí e uma das poucas do Nordeste. Ela foi criada com um acervo de cerca de mil invertebrados, 2600 vertebrados e, ainda, 8.000 volumes, incluindo livros, monografias (TCCs, dissertações e teses) e periódicos nacionais e internacionais. O referido acervo inicial foi originado de uma doação realizada por uma ONG no ano de 2009 e é composto por espécimes de diferentes regiões do Brasil (especialmente das regiões Sudeste e Norte) e de outras partes do mundo (ex.: África). Assim, esses dados demonstram a importância dessa coleção para o estado do Piauí e para o Nordeste de modo geral, consolidando-a como um local de pesquisa, ensino e extensão, úteis à sociedade e à comunidade acadêmica piauiense.

O PDI também enfatizou a preocupação com A AMPLIAÇÃo DO ACERVO BIBLIOGRÁFICO DO SISTEMA DE BIBLIOTECAS (p. 86, alínea “l”), propondo-se a ampliar, a cada ano, em até $10 \%$, o acervo e/ou tipologia dos serviços prestados. Para tanto, discriminou as suas estratégias de ação, dentre as quais se destacam as seguintes:

- Contratação de recursos humanos (Bibliotecários e Técnicos Administrativos) para possibilitar a ampliação dos serviços;

- Capacitação dos recursos humanos envolvidos com os serviços de biblioteca para aprimoramento do Sistema de Bibliotecas;

- Agregação de novos recursos para uso e disseminação da informação digital. (p. 208).

Atualmente a UFPI conta com um acervo de 70.989 títulos e 205.198 exemplares; a Biblioteca Setorial do Campus de Floriano, que temporariamente funciona em conjunto com o Colégio Agrícola de Floriano, possui um acervo de 3.095 livros e 10.019 exemplares. Em 2009, foram adquiridos 712 novos títulos, correspondendo a 1.966 exemplares, e, no ano seguinte, mais 518 títulos e 2.728 exemplares. No primeiro semestre de 2011, as aquisições correspondem a 658 títulos e 3.712 exemplares; logo, nesse intervalo de tempo foram adquiridos 1.888 títulos e 8.406 exemplares, representando um aumento significativo nesses últimos anos, pois o seu acervo inicial correspondia somente a 1.207 títulos e 1.613 exemplares.

Quanto à ampliação dos serviços por meio da contratação de recursos humanos, ainda não houve grandes avanços, pois a biblioteca possui apenas cinco servidores, uma bibliotecária e quatro assistentes em Administração para atender a uma demanda alta, já que destina-se ao atendimento dos estudantes do Colégio Agrícola e da Universidade Aberta do Piauí (UAPI), apresentando, portanto, deficiência no quesito "recursos humanos". A estrutura 
física da biblioteca do CAFS está adequada e seu acervo vem sendo constantemente atualizado, mas ainda é necessário ampliar o número de servidores para melhor atender à comunidade acadêmica. Precisa-se também de um laboratório de internet, um laboratório para deficientes visuais, cabines individuais para notebooks e uma videoteca.

TREINAMENTO CONTINUAdo DO PESSOAL DE APOIO (p. 87, alínea “p”):

Neste último quinquênio a expansão das atividades foi acompanhada de contratação de um grande aporte de recursos humanos jovens. Agora, neste quinquênio a atenção será voltada para o treinamento de pessoal a fim de possibilitar o desenvolvimento das atividades necessárias ao crescimento institucional.

A Diretoria de Recursos Humanos da UFPI traçou as políticas destinadas para a intensificação do processo de formação contínua de servidores docentes e técnicoadministrativos, mediante cursos de capacitação e qualificação. Contudo, verifica-se que esse item efetivamente não se concretizou, afinal todos os recursos humanos jovens que vêm sendo contratados não estão recebendo treinamento pessoal conforme previsto no seu plano de ação. Diante disso, vimos que a ação proposta não está muito específica, e que persiste a necessidade de fortalecimento desse item através da inserção de uma base quantitativa para perceber se a meta está sendo efetivada ou não. São necessárias, ainda, políticas voltadas para a descentralização do departamento de recursos humanos, pois se em cada campus houvesse uma equipe própria a identificação das carências locais e, consequentemente, a definição da melhor estratégia a ser seguida, seriam facilitadas.

No CAFS, embora a grande maioria dos servidores técnicos possuam cargo de nível médio, quase todos já possuem título de graduação e de pós-graduação, pois, dos treze servidores técnicos de nível médio, onze já são graduados e, destes, nove são especialistas. Fazem-se necessários, agora, programas destinados à formação continuada desses servidores.

Por fim, o PDI prevê o FORTALECIMENTO dOS PROGRAMAS DE BOLSAS PARA DISCENTES. Esta foi uma ação bem-sucedida, pois os estudantes têm a possibilidade de se envolver em bolsas e garantir a sua permanência na universidade. Conforme a Pró-Reitoria de Assuntos Estudantis e Comunitários (PRAEC), no ano de 2008 foram disponibilizadas 323 bolsas e, em 2010, 1366. Em Floriano, no ano de 2008, foram disponibilizadas somente quinze bolsas permanência; em 2010, esse número corresponde a 140 bolsas. 
Tendo em vista os itens aqui analisados, vimos que 78\% das propostas do PDI foram realizadas ou estão sendo realizadas com êxito e apenas $22 \%$ ainda não se desenvolveram conforme o desejado; é o caso do treinamento continuado do pessoal de apoio e da ampliação dos serviços prestados pela biblioteca.

É importante salientar que o prazo para a concretização dessas propostas ainda não se esgotou, tendo até 2014 para a sua efetivação. Entretanto, faz-se necessário que, para os próximos planejamentos, os gestores procurem definir as suas ações através de estratégias quantitativas e participativas. Vale ressaltar, porém, que, mesmo diante desses pontos que ainda não se concretizaram com sucesso, a UFPI é uma das mais conceituadas universidades do Brasil, e vem atuando com uma gestão híbrida, com traços do modelo burocrático e do modelo gerencialista, mostrando sua preocupação com a eficiência e eficácia dos seus processos, desde o planejamento estratégico até as atividades rotineiras desenvolvidas na instituição.

\section{CONSIDERAÇÕES FINAIS}

Um dos maiores desafios das organizações públicas na atualidade diz respeito à concretização dos objetivos planejados, pois os usuários dos serviços exigem cada vez mais qualidade e transparência nas suas ações, cobrando presteza no atendimento e no cumprimento da missão das instituições.

Diante do exposto, pode-se afirmar que o modelo de gestão adotado e a opção por um planejamento estratégico direcionado efetivamente para a melhoria dos serviços oferecidos são pontos extremamente significativos para o alcance dos objetivos pretendidos. Nota-se, então, que a Universidade Federal do Piauí é uma instituição capaz de gerir estrategicamente as suas ações, pois, como vimos, dentre as propostas ora analisadas, $78 \%$ efetivamente já se concretizaram,

Vimos ainda que, quando se trata de modelo de gestão, a UFPI adota um modelo híbrido, entre a burocracia e o gerencialismo, mas o importante é que essa instituição, independentemente do modelo de gestão adotado, esteja constantemente evoluindo, melhorando a qualidade dos serviços públicos prestados e proporcionando aos cidadãos piauienses a oportunidade de frequentar uma instituição pública de excelência. Esse caminho já vem sendo trilhado, já que, desde 1971, a UFPI vem desenvolvendo políticas direcionadas para o ensino superior e contribuindo significativamente para o crescimento do Piauí. 
Admite-se que, como em qualquer outra instituição, existem deficiências na gestão pública da UFPI. Todavia, é preciso saber lidar com tais problemas e desenvolver políticas públicas a fim de que essas barreiras sejam superadas, de modo que a instituição possa alcançar eficaz e eficientemente a sua missão, qual seja, propiciar a elaboração, sistematização e socialização do conhecimento filosófico, científico, artístico e tecnológico permanentemente adequado ao saber contemporâneo e à realidade social, formando recursos que contribuam para o desenvolvimento econômico, político, social e cultural local, regional e nacional.

\section{REFERÊNCIAS}

ARAGÃO, Cecília Vescovi. Burocracia, eficiência e modelos de gestão pública: um ensaio. Revista do Serviço Público, ano 48, n. 3, set./dez. 1997.

BARBOSA, Emerson Rodrigues; BRONDANI, Gilberto. Planejamento estratégico organizacional. Revista Eletrônica de Contabilidade, vol. I, n. 2, 2005.

BERGUE, Sandro Trecastro. Comportamento organizacional. Florianópolis: Departamento de Ciências da Administração/UFSC; [Brasília]: CAPES: UAB, 2010.

BRASIL. Constituição da República Federativa do Brasil. Brasília, DF: Senado Federal, 1988.

Lei $n^{\circ}$ 9784, de 29 de janeiro de 1999. Regula o processo administrativo no âmbito da Administração Pública Federal. Disponível em: $<$ http://www.planalto.gov.br/ccivil_03/leis/L9784.htm>.

. Ministério da Educação. Programa de Reestruturação e Expansão das Universidades Federais - REUNI. Disponível em: <http://reuni.mec.gov.br/>. Acesso em: 25 set. 2011.

CAMARGOS, Marcos Antônio; DIAS, Alexandre Teixeira. Estratégia, administração estratégica e estratégia corporativa: uma síntese teórica. Caderno de Pesquisas em Administração, São Paulo, v. 10, n. 1, jan./mar. 2003.

CHIAVENATO, Idalberto. Introdução à teoria geral da administração: uma visão abrangente da moderna administração das organizações. Rio de Janeiro: Elsevier, 2003.

. Administração nos novos tempos. 2. ed. Rio de Janeiro: Elsevier, 2010.

COLLIS, Jill; HUSSEY, Roger. Pesquisa em administração: um guia prático para alunos de graduação e pós-graduação. Trad. de Lucia Simonini. 2. ed. Porto Alegre: Bookman, 2005. 
DICIONÁRIO ETIMOLÓGICO. Disponível em:

$<$ http://dicionarioetimologico.com.br/searchController.do?hidArtigo=EABA6D12FFE662E2 B3B27919BD3FEB38>. Acesso em: 19 ago. 2011.

FISCHMANN, Adalberto Américo; ALMEIDA, Martinho Isnard Ribeiro de. Planejamento estratégico na prática. 2. ed. 17. reimpr. São Paulo: Atlas, 2009.

HAMPTON, David R. Administração contemporânea: teoria, prática e casos. Trad. de Lauro Santos Blandy e Antônio C. Amaru Maximiano. 3. ed. São Paulo: Pearson Makron Books, 2005.

LACOMBE, Francisco José Masset; HEILBORN, Gilberto Luiz José. Administração: princípios e tendências. 2. ed. rev. e atualizada. São Paulo: Saraiva, 2008.

LUFT, Celso Pedro. Minidicionário Luft. São Paulo: Ática, 2004.

MAXIMIANO, Antônio Cesar Amaru. Introdução à Administração. 7. ed. rev. e ampl. 3. reimpr. São Paulo: Atlas, 2009.

OSÓRIO, Medina Fábio. Novos rumos da gestão pública brasileira: dificuldades teóricas ou operacionais? Salvador: Revista Eletrônica sobre a Reforma do Estado, 2005.

SANTOS, Rita de Cássia. Plano plurianual e orçamento público. Florianópolis:

Departamento de Ciências da Administração/UFSC; [Brasília]: CAPES: UAB, 2010.

SCHMITT, Daniel Mártin; FIATES, Gabriela Gonçalves Silveira. Modelos de gestão pública: uma análise crítica do modelo utilizado pelo Tribunal de Justiça de Santa Catarina.

Disponível em:

$<h t t p: / / w w w . t j s c 25 . t j . s c . g o v . b r / a c a d e m i a / a r q u i v o s / D a n i e l \_M a r t i n \_S c h m i t t . p d f>$. Acesso em: 15 jul. 2011.

SECHI, Leonardo. Modelos organizacionais e reformas da administração pública. Rio de Janeiro: Revista de Administração Pública, 2009.

UFPI, Universidade Federal do Piauí. Plano de Desenvolvimento Institucional (PDI) 20102014 / Universidade Federal do Piauí. Teresina: EDUFPI, 2010. 232 p.

. Plano de Gestão - UFPI-2008. Teresina: Gráfica da UFPI. 62 p.

. UFPI em números 2011. Disponível em:

$\overline{<\mathrm{http}: / / w w w}$.ufpi.br/page.php?id=158>. Acesso em: 25 set. 2011.

. PRÓ-REITORIA DE ASSUNTOS ESTUDANTIS E COMUNITÁRIOS -

PRAEC. Relatório de Atividades PRAEC/2010. Disponível em:

$<$ http://www.ufpi.br/praec/index/pagina/id/4014>. Acesso em: 25 set. 2011.

WEBER, Max. Economia e sociedade: fundamentos da sociologia compreensiva. 4. ed. Brasília: UnB, 2000. v. 1. 